\title{
Genotype and Maturity Stage Affect the Content and Composition of Polyamines in Tomato-Possible Relations to Plant and Human Health
}

\author{
Evelyn E. Villanueva Gutierrez ${ }^{1,2} \mathbb{D}$, Eva Johansson ${ }^{1, *(\mathbb{D}}$, Alberto Centellas Quezada ${ }^{2}$, Karl-Erik Gustavsson ${ }^{1}$ \\ and Marie E. Olsson ${ }^{1}$ \\ 1 Department of Plant Breeding, Swedish University of Agricultural Sciences-Alnarp, P.O. Box 190, \\ 23422 Lomma, Sweden; Evelyn.Villanueva@slu.se or villanuevaevelyne@gmail.com (E.E.V.G.); \\ Karl-Erik.Gustavsson@slu.se (K.-E.G.); Marie.Olsson@slu.se (M.E.O.) \\ 2 Departmento de Fitotecnia, Facultad de Ciencias Agricolas, Pecuarias y Forestales "Dr. Martín Cárdenas", \\ Universidad Mayor de San Simón, Cochabamba P.O. Box 4894, Bolivia; alberto.centellas@gmail.com \\ * Correspondence: Eva.Johansson@slu.se; Tel.: +46-761285737
}

check for updates

Citation: Gutierrez, E.E.V.;

Johansson, E.; Centellas Quezada, A.; Gustavsson, K.-E.; Olsson, M.E. Genotype and Maturity Stage Affect the Content and Composition of Polyamines in Tomato-Possible Relations to Plant and Human Health. Horticulturae 2021, 7, 300. https:/ / doi.org/10.3390/horticulturae7090300

Academic Editor: Yuyang Zhang

Received: 3 August 2021

Accepted: 6 September 2021

Published: 9 September 2021

Publisher's Note: MDPI stays neutral with regard to jurisdictional claims in published maps and institutional affiliations.

Copyright: (c) 2021 by the authors. Licensee MDPI, Basel, Switzerland. This article is an open access article distributed under the terms and conditions of the Creative Commons Attribution (CC BY) license (https:// creativecommons.org/licenses/by/ $4.0 /)$.

\begin{abstract}
Polyamines (PAs) are molecules affecting several physiological characteristics in all living organisms with cell protective effects, thereby impacting plant and human health. Here, we used HPLC-DAD-ESI-MS to evaluate the content and composition of PAs in eight tomato genotypes over their maturation period, and related the content and composition to other quality traits and possible implications for plant and human health. The tomato genotype, maturity stage and their interactions, significantly affected the content and composition of PAs. Two of the genotypes, 'Huichol' and 'Rio Grande' showed consistently lower levels of $P A s$ than the other evaluated genotypes. The variation in content and composition of $P A s$ among genotypes was found to vary inconsistently over the maturation period. Putrescine content in the different genotypes either did not vary significantly, increased, or showed the lowest level in the middle of the maturation period, while spermidine content decreased or did not show significant variation. The genotypes 'HT36' and 'HT25' showed high levels of $P A s$ during red and green maturity stages, respectively, and can thereby be seen as suitable health promoting red and green candidate tomatoes. Depiction of variation of the PAs creates opportunities for breeding and production of health promoting tomato as a food or food additive.
\end{abstract}

Keywords: putrescine; spermidine; spermine; ascorbic acid; titratable acidity; total soluble solids

\section{Introduction}

Polyamines (PAs) are low molecular weight aliphatic (non-aromatic), nitrogen rich, hydrocarbon molecules that form polymers containing one or more amino group $\left(\mathrm{NH}_{2}\right)[1,2]$. $P A s$ are universally present in all living organisms, including all types of plants, and the naturally abundant $P A s$ (putrescine $(P u t)$, spermidine $(S p d)$ and spermine $(S p m)$ ) are the most common [3,4]. PAs are involved in functions such as cell growth, gene regulation, and differentiation [5]. In plants, biosynthesis or catalysis of $P A s$ have been related to growth, flowering, and stress signaling [6]. During fruit development in tomato, transcripts of $P A s$ biosynthesis genes have been localized in fast growing tissues, and it has been suggested that the seed is a site of intense PA synthesis [7]. Put is the precursor of Spd, which in turn is the precursor of Spm [6]. Several studies have indicated the content of free and conjugated $P A s$ to increase at biotic and abiotic stress conditions [6,8], suggesting that PAs exert a positive effect on the antioxidant system, resulting in a reduction in cellular damage by the capturing of free reactive oxygen species (ROS) [8]. PAs interact with macromolecules, act as osmolytes, and may play a role in biotic stress as regulators of gene expression [9].

In tomato plants, PAs play an active role during stress conditions, e.g., PAs content (especially $S p m$ ) correlated negatively to the amount of ROS and damage tissue under drought conditions [8]. Transgenic tomato plants have been used to verify the positive 
correlation of increased levels of $P A s$ with the content of lycopene, vine life, and juice quality [10]. PAs have also been shown to enhance shelf life in, e.g., apricot and tomato, when externally applied, by suppressing ethylene production [11], thereby acting as a senescence delay compound [10].

In humans, significant amounts of PAs are supplied by foods and absorbed in the small intestine, while microbiota are considered to affect the content of PAs in the large bowel [12]. At present, no daily intake recommendations of $P A s$ are available, but it is well known that the majority of Put and Spd consumed by humans originate from plant-based products while Spm comes from animal-derived food [13].

Furthermore, PAs are suggested to have an impact on human health [3]. Potential health effects from Put, Spd, and Spm as dietary sources have been investigated, although such relationships require further elucidation. A negative association between dietary polyamines and cardiovascular disease has been found [14]. Recent studies have shown a cardio-protecting effect from supplementation with $S p d$, which has been explained by its stimulation of mitochondrial respiration, autophagy and mitophagy [15]. In addition, intake of $P A s$ have been associated with inhibiting processes related to aging. Spd has been found to increase the life span of multi-cellular organisms, such as nematodes, flies and mice [16]. A study with increased intake of Spm and Spd in aged mice found reduced levels of pro-inflammatory markers, age-associated DNA methylation, and mortality [17]. Further, in a 20 year study of a cohort of 829 human participants, spermidine showed the strongest inverse relation with mortality among 146 nutrients investigated [18]. In contrast to these positive effects, PAs have been suggested to have procarcinogenic properties in cancer patients, since polyamine concentrations caused by enhanced biosynthesis have been found in several cancers [16,18-21]. In cancer diagnosed patients, consumption of PAs increased the risk of cancer cell proliferation [22,23] or increased the malignant cell growth rate in established tumors [22]. The connection between PAs and cancer therapy and treatments has resulted in an increased interest in understanding how the polyamine metabolism can be of use in anticancer strategies [24]. However, for healthy individuals, a recent review concluded that a consensus is being reached that polyamine intake does not induce cancer [19]. Some investigations point to an inverse relationship between colorectal cancer and polyamine intake, though this was not found in postmenopausal women with BMIs above $25[25,26]$. Several publications analyze the pros and cons of promoting $P A s$ intake to increase longevity as well as prevention of new tumor formation in healthy subjects $[20,27,28]$.

Horticultural crops are a good general source of vitamins, minerals and fibers among other compounds [28,29]. Many of these vegetables and fruits constitute substantial sources of PAs [30-32]. The effect of biotic or abiotic stressors on PAs composition has been addressed within the same species [33-35] or between spices [36-38]. However, reports on literature of $P A s$ composition during different maturation stages within the same species are scarce. Tomato (Solanum lycopersicum spp.) is a major horticultural crop cultivated across the world, both in open fields and in green-houses to satisfy the increasing demand worldwide [39]. Tomato is highly appreciated by humans, consumed either as fresh produce or as an ingredient [40], and it holds a relatively high content of nutrients, e.g., amino acids, vitamins and minerals [41]. A few previous studies have evaluated the content of PAs in tomatoes, indicating that PAs [19], and specifically Spm [24], increase during early maturation and thereafter decrease. The varying content of $P A s$ over the maturation period in tomato, together with the positive relationships reported for PAs impact on human health [3], indicates opportunities to tailor nutritive tomatoes for improved public health. Furthermore, genotype variation in the content of $P A s$ has been shown [42], which might also have an impact on the variation of content over the tomato maturation period. To our knowledge, studies on interrelationships of PAs in various genotypes and over the full maturation time in non-stressed plants are scarce.

Several studies have shown relationships between the content of $P A$ s with the content of ascorbic acid [36], as well as with lycopene content and ethylene production [43]. In- 
creases in ethylene content is a physiological signal to promote fruit maturity in tomato [42]. A full comparison of PAs content and quality traits in tomatoes [44-46], such as firmness, freshness, shape, ascorbic acid, total soluble solid contents, titratable acidity and color, and effects of maturation has not been carried out. Based on the impact of tomato consumption and opportunities to tailor nutrition and quality in tomato for different purposes, a better understanding of variation in PAs over genotypes and maturation stages, and relation to other quality traits, is of outmost importance.

Thus, the aim of the present study was to evaluate the effect of tomato genotype and maturity stage on the content and composition of PAs in tomatoes. A second aim was to compare levels and composition of $P A s$ with levels of other quality traits in tomatoes. Furthermore, the possible impact of $P A s$ in various tomato genotypes at various maturity stages as biomolecules affecting plant development and health, and their effect on human health, is discussed.

\section{Materials and Methods}

\subsection{Plant Material, Growing Conditions and Sampling}

The tomato genotypes evaluated in the present study comprised four commercial genotypes; 'Lia' (seed producer; Hazera-Seeds of growth), 'Shanty' (Hazera-Seeds of growth), 'Huichol' (Seminis), and 'Rio Grande' (reproduced from the Bolivian National Center of Horticultural Seed Production CNPSH), and four genotypes developed by CNPSH; 'HT23', 'HT25', 'HT36', 'HT37'. The four commercial genotypes were selected as they are the preferred genotypes chosen by Bolivian tomato growers, recognizing them as holding favorable traits, e.g., size, elongated shape, diseases resistance, and suitability for local production conditions or market demand. The HT genotypes are advanced lines of which 'HT23' and 'HT25' meet the quality standards required from Bolivian growers, and 'HT36' and 'HT37' have a higher yield than the other genotypes in the present study. A total of thirty seeds from each genotype were germinated and thereafter five healthy plants were selected from each genotype for further cultivation to sample 3-4 replicates at each of six maturity stages. The plants were cultivated separately in $7.5 \mathrm{~L}$ pots in a greenhouse at $\pm 24{ }^{\circ} \mathrm{C} / 19^{\circ} \mathrm{C}$ day / night temperature, $16 / 8 \mathrm{~h}$ (light/dark conditions) and $60 \% \mathrm{RH}$. A combination of natural light and HPS lamps with 100 to $150 \mu \mathrm{mol} / \mathrm{m}^{2} / \mathrm{s}$ were used, and plants were fertigated and irrigated using an automatic daily ferti-irrigation system.

Tomatoes of each genotype were sampled at different maturity stages; green $(g)$, breaker $(b)$, turning $(t)$, pink $(p)$, light red $(l r)$, and red $(r)$ (Figure S1), based on the visual aid TM-L1 developed by the U.S. Department of Agriculture (USDA) [47]. A total of three to four tomatoes were sampled from each genotype at each maturity stage, and these were evaluated for their shape, fresh weight, and firmness immediately after harvest. The shape was determined according to IPGRI and OPOV [48]. Then, the tomatoes were chopped and for each genotype the tomatoes were divided into four equal portions. One portion was used immediately to process samples to analyze ascorbic acid and another portion was stored at $-20^{\circ} \mathrm{C}$ and was later used for the analyses of $\mathrm{pH}$, color, titratable acidity (Ta), and total soluble solids (Tss). The remaining portions were stored at $-80^{\circ} \mathrm{C}$ for further analysis of $P A s$.

\subsection{Reagents}

Putrescine (Put; ref no 51799-100MG) was purchased from Sigma-Aldrich (St. Louis, MO, USA). Spermidine trihydrochloride was brought from Thermo Fisher Acreos Organic (NJ USA). Spermine tetrahydrochloride was purchased from ICN Biomedics inc (Morrow, $\mathrm{OH}, \mathrm{USA}$ ). Dansyl chloride and 1,7-diaminoheptane were purchased from ThermoFisher (Schnelldorf, BY, Germany). Acetonitrile for HPLC LC-MS grade, L(+)-ascorbic acid, sodium bicarbonate $\left(\mathrm{NaHCO}_{3}\right)$, and dithiothreitol were bought from VWR Chemicals (Leuven, VLG, Belgium, Radnor, PA, USA, and Lutterworth, Leics, England). Ammonium acetate, ethyl acetate $99.8 \%$, hydrochloric acid, methanol, meta-phosphoric and sodium hydroxide were provided from Merck (Darmstadt, HE, Germany). Sodium carbonate was 
obtained from PanReac Applichem (Darmstadt, HE, Germany). Dipotassium hydrogen phosphate, and potassium dihydrogen phosphate were brought from Duchefa (Haarlem, $\mathrm{NH}$, The Netherlands).

\subsection{Fruit Weight and Firmness}

Each fresh tomato fruit was separately weighed on a digital balance and the firmness was measured by a fruit pressure tester (FT 327, Effegi, Italy). Then, the average fresh weight and the average firmness of the three to four tomatoes from each genotype and maturity stage were calculated.

\subsection{Ascorbic Acid (Aa) Analysis}

The $A a$ is one of the most well studied compounds in most fruits and vegetables, including tomatoes, and the content is known to correlate negatively with maturation in tomato [23], which justifies the analysis of its content in the present study. Here, the $A a$ content of the tomatoes was analyzed according to Bergquist et al. [49] with some modifications. Thus, extraction was carried out in a dim green light dark room. A total of $5 \mathrm{~g}$ of chopped tomatoes and $25 \mathrm{~mL}$ of $1.5 \%$ meta-phosphoric acid were added to a $50 \mathrm{~mL}$ brown conical flask. Samples were homogenized for $60 \mathrm{~s}$ using an Ultra-turrax IKA TP 18/10 (Werke GmbH \& Co. KG Staufen, Germany), and thereafter they were kept cold $\left(4^{\circ} \mathrm{C}\right)$ and dark for 60 min before centrifugation (Eppendorf $5427 \mathrm{R}$; Hamburg, Germany) at $12,900 \times \mathrm{g}$ for $10 \mathrm{~min}$. Then, $1.7 \mathrm{~mL}$ of the supernatant aliquot of each sample was stored at $-80^{\circ} \mathrm{C}$ until HPLC analysis. For the HPLC analysis, samples were thawed and centrifuged, and an aliquot of $500 \mu \mathrm{L}$ of the supernatant was mixed with $500 \mu \mathrm{L}$ of dithiothreitol $(11 \mu \mathrm{g}-\mu \mathrm{L})$ to reduce dehydroascorbic acid to ascorbic acid. The samples were then centrifuged at $8944 \times g$ for $2 \mathrm{~min}$ at room temperature, and placed in amber vials. $A a$ stock solution $(50 \mu \mathrm{g}-\mathrm{mL})$ was treated the same way as the samples. HPLC analyses were carried out using an Agilent Technologies 1260 Infinity HPLC system (CA, USA). Vials were placed in a thermostated autosampler and an aliquot of $10 \mu \mathrm{L}$ was injected on a Phenomenex (Torrence, CA, USA) Synergi Polar-RP $80 \AA$ A, LC column $(4.6 \times 50 \mathrm{~mm}, 4 \mu \mathrm{m})$. The eluent buffer consisted of methanol $(4 \%)$ and $\mathrm{KH}_{2} \mathrm{PO}_{4}$ solution $(20 \mathrm{mM})$ at $\mathrm{pH} 2.3$. Standards and samples were run in an isocratic mode with a flow rate of $1 \mathrm{~mL} / \mathrm{min}$ for $14 \mathrm{~min}$ and with a wavelength of $248 \mathrm{~nm}$. The amount of ascorbic acid was quantified from comparisons with the standard curve.

\subsection{Color Measurement, Total Soluble Solids (Tss), pH, and Titratable Acidity (TA)}

Skin pieces of tomatoes were thawed and color at each maturity stage was evaluated as $\mathrm{L}^{*}$ for value for lightness, Chroma for brightness, $\mathrm{a}^{*}$ value, and $\mathrm{b}^{*}$ value for red/green color and yellow/blue color, respectively [50,51], with a Chromameter Apparatus Konica Minolta CR-400 (Osaka, Japan). A representative sample of each tomato genotype at each maturity stage was used to produce pure tomato juice, from which Tss was evaluated in four replicated samples by a digital refractometer RFM80 (Wells, UK). Each juice sample was then diluted with distilled water (1:4) for measurement of $\mathrm{pH}$ and $\mathrm{Ta}$ by a digital titrator (Titroline Schott Instruments apparatus, Germany). For Ta measurements, a working solution of $50 \mathrm{mM} \mathrm{NaOH}$ and endpoint of the reaction of $\mathrm{pH} 8.3$ was used. The Tss/Ta ratio is a comprehensive predictor of flavor [52] and this ratio was calculated by dividing $\%$ Tss with $\% \mathrm{Ta}[53]$.

\subsection{Polyamines Analysis}

In plants, the majority of polyamines are present in their free form [54]. This study isolated and quantified free $P A s$, a combination of methods developed previously was used [55-58] and with modifications as follows: standards of Put, Spd, and Spm were prepared separately, by diluting each of them in millipore ultrapure water, storing them at $-20{ }^{\circ} \mathrm{C}$, and thereafter mixing $25 \mu \mathrm{L}$ of each diluted polyamine with $925 \mu \mathrm{L}$ of a premixed solution made of $\mathrm{HCl}(1 \mathrm{M})$ and the internal standard 1,7-diaminoheptane $(30 \mu \mathrm{g} / \mathrm{mL})$. 
Before and during analysis, the standard solution $(100 \mu \mathrm{g} / \mathrm{mL})$ was treated the same way as the tomato samples extracted for polyamine analysis. Tomato samples of different genotypes and maturity stages were lyophilized at $-105^{\circ} \mathrm{C}$ (CoolSafe TM SCANVAC) until a steady weight was achieved. Lyophilized samples were homogenized to a powder in an Ultra centrifugal mill (ZM 200 RETSCH GmBH; Haan, Germany) equipped with trapezoid sieve holes of $0.5 \mathrm{~mm}$ pore size, at $2016 \mathrm{~g}$. The powder was then kept at $-80{ }^{\circ} \mathrm{C}$ until polyamine extraction.

The extraction of free polyamines was carried out according to Buranaphalin [59] with some modifications. Thus, $50 \mathrm{mg}$ of a representative powder sample of each tomato sample (genotype and maturity stages) was placed in a Eppendorf tube and thereafter $1000 \mu \mathrm{L}$ of $1 \mathrm{M} \mathrm{HCl}$ and $30 \mu \mathrm{g}-\mathrm{mL}$ of 1,7-diaminoheptane (internal standard) was added. Samples were homogenized with a vortex (Combi-spin FVL-2400, Biosan, Latvia) for $30 \mathrm{~s}$ and ruptured by a sonication-shear bath (Bandelin Sonorex digitec DT 100 H, Bandelin, Germany) for $5 \mathrm{~min}$. Thereafter, a cold extraction was carried out using an incubation period of $1 \mathrm{~h}$ followed by centrifugation at $4{ }^{\circ} \mathrm{C}$ for $10 \mathrm{~min}$ at $12,900 \times g$ (Eppendorf $5427 \mathrm{R}$ Hamburg, Germany).

Dansylation of the polyamines was performed as follows: In an aliquot of $200 \mu \mathrm{L}$ of supernatant from the hydrochloric extraction performed previously, $300 \mu \mathrm{L}$ of saturated $\mathrm{NaHCO}_{3}, 100 \mu \mathrm{L}$ of $2 \mathrm{M} \mathrm{NaOH}$, and $600 \mu \mathrm{L}$ of dansyl chloride $(5 \mathrm{mM})$ were added. Treated samples were then mixed thoroughly with a vortex for $30 \mathrm{~s}$, thereafter heated for $45 \mathrm{~min}$ at $60^{\circ} \mathrm{C}$ in a heating bath with circulator (MS/2 Lauda, Königshofen, Germany), and then placed immediately in cold conditions until the liquid-liquid extraction was carried out.

Liquid-liquid extraction (LLE) was performed by adding $500 \mu \mathrm{L}$ of pure ethylacetate to the dansylated sample, followed by homogenization with a vortex for $30 \mathrm{~s}$ and centrifugation for $1 \mathrm{~min}$ at room temperature. Thereafter, the supernatant was transferred to a new $2 \mathrm{~mL}$ Eppendorf tube. The same procedure was repeated twice on the same sample, and the two additional supernatants were pooled to the first one in the same Eppendorf tube. The pooled samples were evaporated using a water bath evaporator (TurboVap LV Biotage Charlotte, USA). The dry samples were thereafter resolved in $100 \mu \mathrm{L}$ of pure acetonitrile, the samples were homogenized in a vortex for $30 \mathrm{~s}$ and centrifuged for $5 \mathrm{~min}$ at $12,900 \times g$ at room temperature. An aliquot of each sample was transferred to an amber vial for HPLC-DAD-MS analysis.

An HPLC-DAD-MS 1260 infinity system from Agilent Technologies (CA, USA) equipped with a diode array detector (DAD) G4212, and a single Quadrupole $6120 \mathrm{~b}$ run at $100^{\circ} \mathrm{C}$, equipped with an electrospray ion source with drying gas $\mathrm{N}_{2}(12 \mathrm{~L}-\mathrm{min})$ at a gas temperature of $300{ }^{\circ} \mathrm{C}$, and nebulizer $30 \mathrm{psig}$ run in positive mode, was used for the analyses. The $P A s$ were separated using a reverse-phase column $2.1 \times 50 \mathrm{~mm}, 1.8 \mu \mathrm{m}$ Agilent Zorbax SP (Santa Clara, USA) operated at $40^{\circ} \mathrm{C}$ with an injection volume of $10 \mu \mathrm{L}$ per sample.

The mobile phase used consisted of Eluent A: ammonium acetate $100 \mathrm{mM}$ and Eluent B: pure acetonitrile, with the gradient as follows: $0-13 \min 80-14 \%$ A, 13-14 $\min 14-80 \%$ A, $14-17 \mathrm{~min} 80 \% \mathrm{~A}$, and a constant flow rate of $500 \mu \mathrm{L} / \mathrm{min}$. HPLC-DAD-MS analysis: DAD was carried out using a wavelength of $221 \mathrm{~nm} \pm 4 \mathrm{~nm}$ for quantification of dansylated PAs. MS was run in SIM mode $(\mathrm{M}+\mathrm{H})^{+}$. Identification of PAs was as follows: Put: 556.60, internal standard (Is): 597.80, Spd: 846.90, and Spm: 1138.30 in all samples. For data acquisition, the Chemstation software (B04.03-SP1, Ver87, Agilent Technologies, Waldbronn, Germany) was used. Table S1 shows the mass calculation used for Put, Spd and Spm bound to dansyl chloride. Total polyamines (Tpa) was calculated as the sum of Put, Spd, and Spm. A chromatogram of the standards (Figure S2a) and a representative chromatogram (Figure S2b) of the analyzed tomato samples is included as Figure S2.

\subsection{Statistical Analysis}

Statistical analysis was performed using R 3.5.2 with the packages, emmeans, factoextra, and ggplot2. Data were evaluated with the Shapiro normality test before statistical analysis. All study sample data were subject to analysis of variance (ANOVA) in a general 
linear model including the factor genotypes, maturity stages, and interaction between genotype and maturity stage. Factors were considered statistically significant if $p \leq 0.01$. Differences between means were evaluated using Tukey posthoc test with a significance level of 0.05. Principal component analysis (PCA) was used to find relationships between $P A s$ and conventional quality parameters in different genotypes, and at different stages.

\section{Results and Discussion}

The eight genotypes evaluated showed significant differences in type, form and color, as visualized in Figure 1.

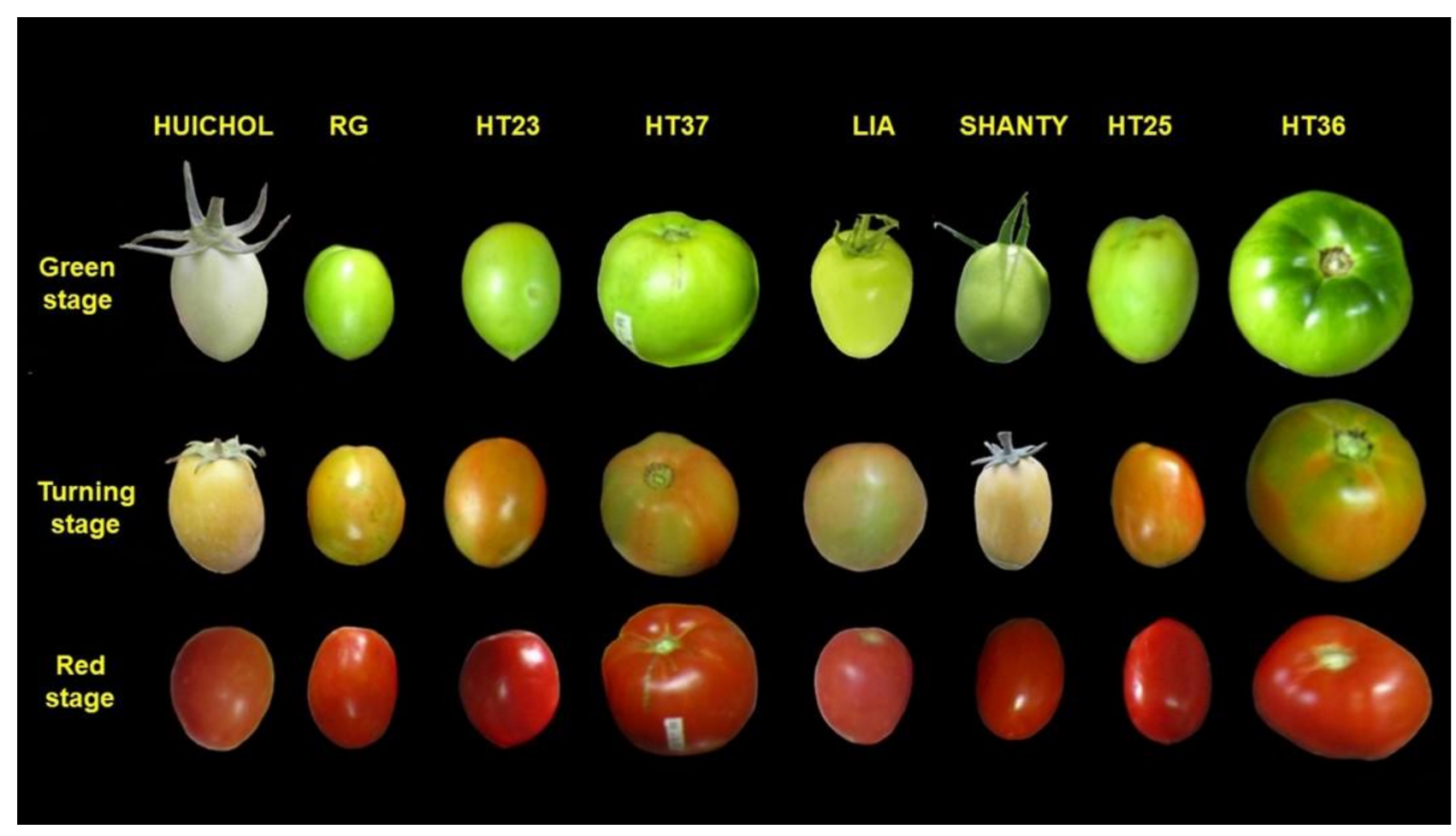

Figure 1. Tomato fruits of eight genotypes (From left to right: 'Huichol', 'Rio Grande' (RG), 'HT23', 'HT37', 'Lia', 'Shanty', 'HT25' and 'HT36') at three maturity stages (green, turning and red).

The ANOVA analysis (Table S2) showed a significant impact of tomato genotype, maturity stages, and their interactions on practically all analyzed parameters. Thus, although studies on genotypic and environmental effects on content and composition of PAs in tomatoes are scarce, our results correspond with those of other studies on other components and other crops [60-66]. Genotype differences are known to have an impact on a large number of quality parameters and components in almost any crop [60,61]. The level of the impact from the genotype is related to the type of quality characteristic evaluated and how broad a genetic variation is included in the selection of the plant material analyzed [62]. Additionally, the maturity stage has been verified as having a high impact on a range of quality parameters in a vast array of crops $[63,64]$. Furthermore, interactions between genotype and maturation stages are commonly seen in other studies $[65,66]$.

Principal component analyses (PCA) revealed differentiation of components related to maturity along the first principal component axes (PC1—explaining $34 \%$ of the variation). Chroma, $\mathrm{a}^{*}$ and $\mathrm{b}^{*}$ values, total soluble solids (Tss) and titratable acidity (Ta) were all found with positive PC1 values and all of these components are known from previous studies with a positive correlation to maturity in tomatoes [67-70]. Furthermore, firmness and $\mathrm{L}^{*}$ values, found with negative PC1 values, are known to correlate negatively with maturity in tomatoes $[67,71]$. Both the total polyamines content (Tpa) and amount of the different polyamines (putrescine $(P u t)$, spermidine $(S p d)$ and spermine $(S p m)$ ) were found 
to have positive values for the second principal component (PC2-explaining 20.3\% of the variation), indicating variation in PC2 to be in principal determined by the PAs content and composition. However, values of PC1 were positive for Tpa and Put while negative for Spd and Spm. Thus, maturity of the tomatoes might influence the content of PAs, with tomato maturity being positively correlated with $T p a$ and $P u$ and negatively correlated with Spm and Spd. The relationships between PAs and tomato maturity indicated by our PCA correspond well with previous results in transgenic tomatoes, where increased levels of Spd in the fruits delayed maturity [72].

The PCA loading plot (Figures 2B and S3) further verified the differentiation of tomato maturity along the PC1, with green and break stages of the tomatoes having negative PC1 values; turning and pink stages with neutral and light red and red stages with positive PC1 values. Thus, a comparison of the score and loading plot results in high levels of firmness and $\mathrm{L}^{*}$ values in green and break stages of tomatoes and high Chroma, $\mathrm{a}^{*}$ and $\mathrm{b}^{*}$ values, Tss and Ta in light red and red stages of tomatoes, which also verifies previous results $[45,69,73]$. The genotypes in the present study showed a differentiation along the PC2 direction, indicating differences in the content of PAs (compare Figure 2B with Figure 2A), with high levels in the genotype 'HT37' through all maturation stages. Studies on PAs content and composition in tomatoes of different maturation stages are rare and mostly reported over a narrow range of tomatoes $[36,72,74]$, although genotype variation has been reported in some studies on mature tomatoes [75-77]. The tomatoes evaluated in the present study generally showed high levels of polyamines, especially of Put and Spd, as compared to values reported in most other studies (Table S3). However, as genotype, cultivation conditions as well as experimental conditions are known to effect the content of $P A s$ reported in tomatoes, such factors may also impact on the differences from various studies reported here.

Previous studies [74], have indicated a role of $P A$ s for the determination of the fruit architecture, i.e., expression of yeast spermidine synthase ( $S p d s)$ under tomato maturation, resulted in increased levels of obovoid fruits. In this study, tomato genotypes of various shapes and with different content and composition of PAs were included, although the limited number of genotypes of various shapes hindered a more thorough comparison of such relationships.

Comparison of mean values showed the effect of tomato genotype and maturation period on the content and composition of Tpa, Put, Spd and Spm (Figure 3 and Table S4). Thus, a y low level of Tpa, Put and Spd were found in genotypes such as 'Huichol' and 'Rio Grande', while a generally higher amount was found in the other evaluated genotypes. Changes in $P A s$ over the maturation time varied inconsistently for the different genotypes evaluated here (Figure $3 \mathrm{~A}$ ). The content of $P u t$ was either showing no significant differences in the tomatoes along the maturation period or showing a significant increase over the maturation period, e.g., in 'Huichol', 'Rio Grande' and 'HT36' to a final content of 155, 133 and $1855 \mu \mathrm{g} / \mathrm{g} / \mathrm{DW}$, respectively (Figure 3B). Indications of a decrease in Put content in the middle of the maturation time was also found in 'Lia' and 'Shanty' with high values at the $g$ and $r$ stages (Figure 3B). The content of Spd showed either no significant variation over the maturation period or a significant decrease over the maturation period, e.g., in 'Huichol', 'HT23', 'Lia', 'Shanty' and 'HT25' (Figure 3C). Spm showed either no variation or a decrease ('HT23', 'Lia', 'Shanty' and 'HT36') over the maturation period. Thus, for Tpa over the maturation period, the different changes found in the individual polyamines led to no significant changes ('Huichol', 'Rio Grande', 'HT23', and 'HT37'), a decrease in the middle of the maturation period ('Lia'), or increases ('HT36') and decreases ('Shanty' and 'HT25') over the maturation period (Figure 3 and Table S4). 

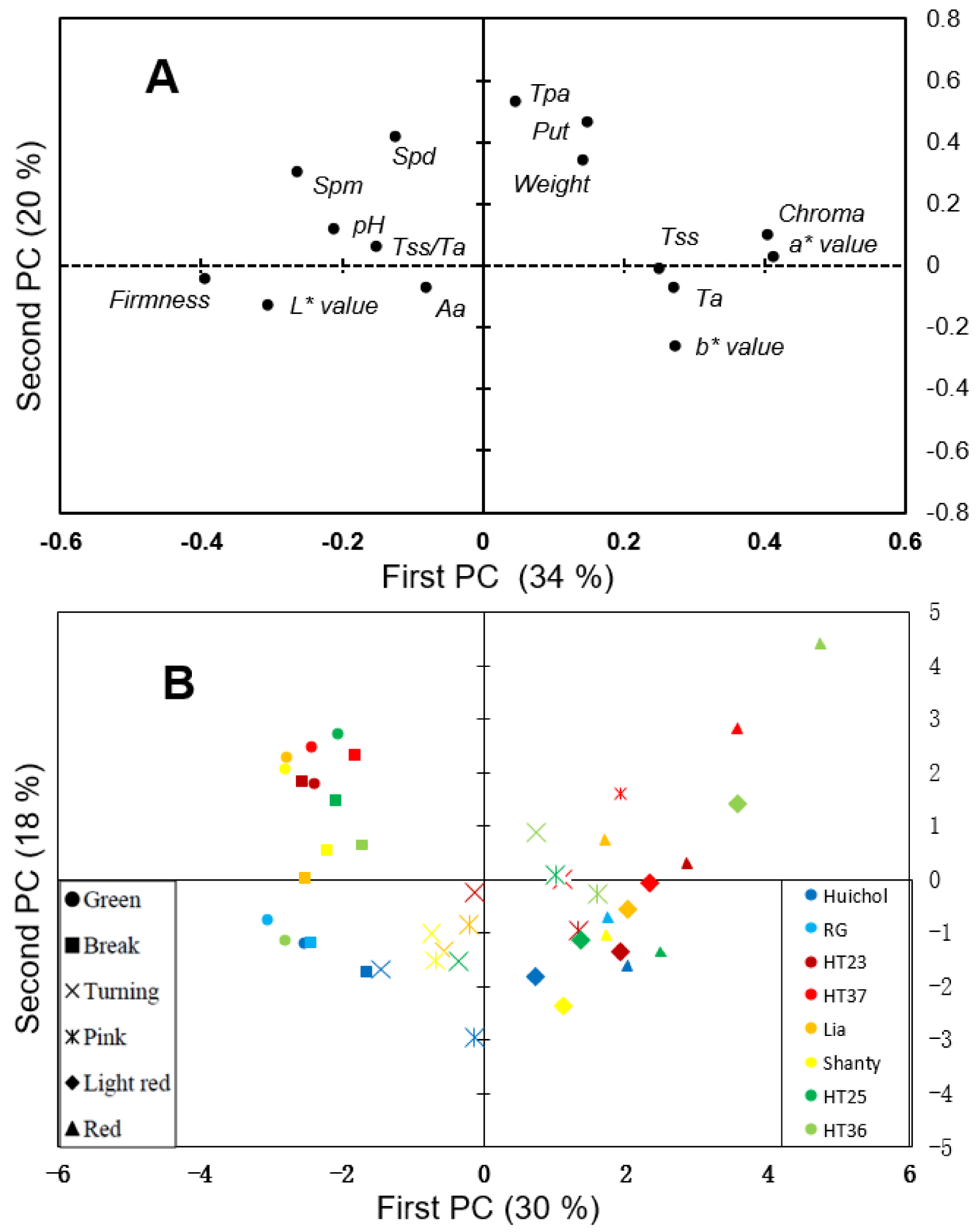

Figure 2. Score (A) and loading (B) plots generated from PCA on all and mean values, respectively, of quality traits (Chroma (brightness), $\mathrm{a}^{*}$ value (redness), $\mathrm{b}^{*}$ value (blueness), $\mathrm{L}^{*}$ value (lightness), TSS (total soluble sugar), Ta (titratable acidity), TSS / Ta (total soluble sugar and titratable acidity ratio), $A a$ (ascorbic acid), Firmness, $\mathrm{pH}$ and Weight) and polyamines contents (Tpa (total content of polyamines), Put (putrescine), Spd (spermidine), Spm (spermine)) of eight genotypes 'Huichol', 'Rio Grande (RG)', 'HT23', 'HT37', 'Lia', 'Shanty', 'HT25', and 'HT36' (marked with different colors) at six maturity stages (marked with different symbols). Loading plot on data from each tomato evaluated are shown in Figure S3. 

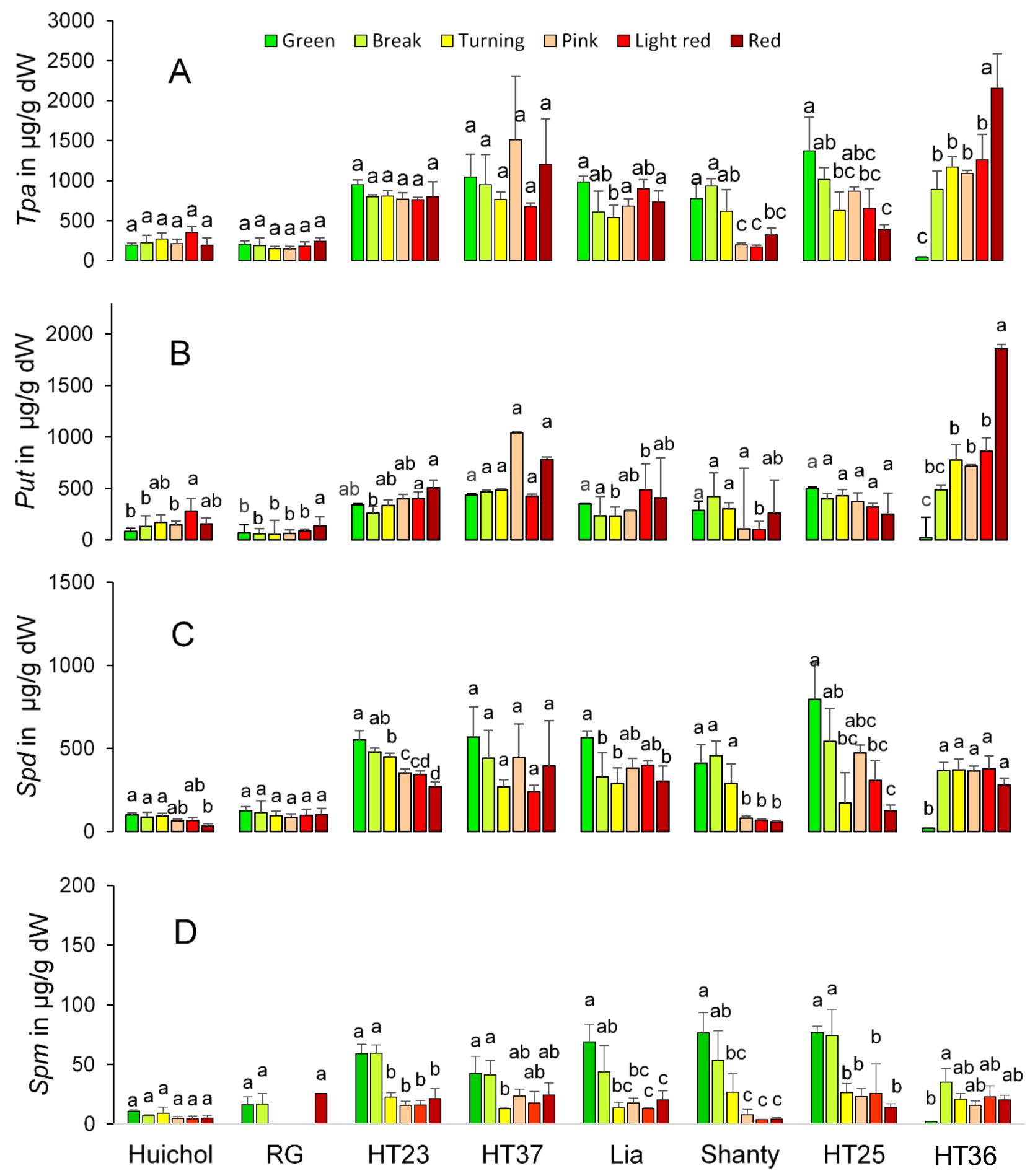

Figure 3. Content of Tpa (total polyamines (A)), Put (putrescine (B)), Spd (spermidine (C)) and Spm (spermine (D)) in $\mu \mathrm{g} / \mathrm{g}$ $\mathrm{dW}$ of eight tomato genotypes ('Huichol', 'Rio Grande' (RG), 'HT23', 'HT37', 'Lia', 'Shanty', 'HT25' and 'HT36') at six maturity stages (green, break, turning, pink, light red and red). Values are the average of three to four samples. Bars indicate standard deviations. Letters above the staples that differ indicate significant differences ( $p<0.05$ using Tukey post hoc test) between tomatoes of different maturity stages within the same genotype. A comparison of statistical differences among mean values of all genotypes and stages is shown in Table S4.

A possible developmental inter-relationship between $P A s$ and ethylene has frequently been discussed as they share a common substrate, S-adenosylmethionine (SAM), for their biosynthesis. The possible competition for the substrate SAM, as well as their suggested potential opposite functions as pro-senescence/pro-ripening for ethylene and pro-growth 
for $P A s$, make these compounds interesting in relation to understanding fruit ripening and senescence processes [78]. Early studies indicated that polyamines inhibit ethylene biosynthesis in a variety of fruit tissues $[79,80]$, though later investigations further concluded that the effects of $P A s$ are also dependent on the developmental stage, which part of a plant that investigated and PAs concentrations [78]. It has been suggested that the SAM levels might not be generally rate limiting for the biosynthesis of PAs and ethylene, and their interrelationship rather is developmentally regulated in a tissue- and cell-specific manner [78]. In addition, the different PAs have been suggested to have different functions. The levels of Put are suggested to increase during conditions of low activity, while Spd and Spm act as ripening and growth stimulators, and the ratio Spd/Put could to some extent control ripening, senescence, and quality in climacteric fruits [81]. Further, Put has been indicated to act as a negative regulator while $S p d-S p m$ are positive regulators of cellular amino acid metabolism [82]. In tomato, PAs have been found to influence the expression of genes related to ethylene synthesis, while 1-aminocyclopropane-1-carboxylic acid synthase (ACC) expression was repressed after the exogenous application of PAs [83]. In this study, the decrease in the concentrations of $S p d$ with advancing tomato ripening in five of the cultivars and in Spm in four of the cultivars could be in accordance with these compounds acting as stimulators of growth and ripening. Previous investigations reported that the ethylene concentration peaked at the pink stage of the tomato [84], which in this investigation in some of the cultivars coincided with a drop in the concentration of Spm. In the later ripening stage in tomato, senescence-related genes are activated [85], and the onset of senescence processes could in this investigation be indicated by the lower levels of Spd and Spm in some cultivars, leading to downregulated amino acid metabolism.

Previous studies have reported similar variations in $P A s$ effect of tomato genotype and maturation to the present study. Thus, a steady content of Put during all maturity stages was reported for Lycopersicum esculentum c.v. Indalo [86]. Another study on cherry tomato cv 'Chiou', reported a constant decrease of $P u t$ from $g$ to $b$ stage followed by a constant increase from $b$ to $r$ stage [7]. Decreasing levels of Spd over the maturation time has previously been reported [86]. Most previous studies that have evaluated changes in $P A s$ over the tomato maturation time have focused on only one genotype meaning that the genotypic variation in $P A s$ over maturation time, as the present study is depicting, has not previously been reported.

For the plant, PAs content and composition is reported to effect a range of cellular functions, impacting characteristics such as plant development and response to stresses and extreme environments, plant longevity, content of lycopene, physiological memory, and carbon/nitrogen allocation and signaling [3]. The present study clearly showed differences in the content of PAs between different tomato genotypes and also in patterns of accumulation over the tomato maturation period. Based on the knowledge from the literature, that transgenic tobacco, rice and tomato plants with high accumulation of $P A s$ all showed increased tolerance to a range of stresses including salt and heat $[87,88]$, indicate a possibility that the high PAs content genotypes (all except 'Huichol' and 'Rio Grande') in the present study may have higher tolerance to stresses than low PAs genotypes ('Huichol' and 'Rio Grande'). However, the present study did not evaluate such relationships, although such relationships might be of relevance in the development of stress tolerant tomatoes. Furthermore, studies on transgenic Arabidopsis, pear and potato with overexpression of Spd have shown a positive correlation with tolerance to stresses [88-92]. In the present study, the genotype variation in Spd followed the same pattern as Tpa. An interesting feature is that both $S p d$ and Tpa changed in the tomatoes during the maturation period, and the impact of these differences needs to be further elaborated on when it comes to relationships to cellular functions. Previous studies have indicated that $P A s$ metabolism can be upregulated, downregulated, or moderately expressed, and affect other quality traits depending on the particular maturity stage, genotypes, or even fruit type [93].

Due to the fact that the contents of $P A s$ are known to be effected by external factors and stressors, such environmental conditions can be used to increase or decrease the 
content of PAs in tomatoes. In the present study, all genotypes were grown under the same experimental conditions in a well-controlled environment, providing the same amount of nutrient solutions, light regime, humidity, and temperature. Thus, the environmental conditions are expected to have had a limited effect on the outcomes of the present study. However, environmental conditions can be used to interplay with genetic and maturation parameters to produce tomatoes with certain levels of specific PAs. The present study does, however, show the need for a thorough study into such relationships due to the fact that the different tomato genotypes reacted differently during the maturation period.

The variation in PAs content and composition in various tomato genotypes and over maturation time, depicted in the present study, is also of relevance when it comes to the effects of tomato consumption on human health. A number of studies have indicated positive effects of intake of food with a sufficient amount and composition of $P A s$, as reviewed by Handa et al. [3]. PAs have been shown to positively affect physiological processes connected to normal growth, cardio protection, aging, oxidative stress and loss of memory, as well as a negative correlation with diseases such as cancer, Alzheimer's disease and Parkinson's disease, has been reported [24,94-98]. Based on the many positive health perspectives gained rom the intake of $P A s$, nutritionally high value $P A s$ tomatoes might in the future be of potential interest, either as health food or as food additives. The present study shows the genotype 'HT36' to be an interesting candidate as a health promoting red tomato, while 'HT25' is interesting as a health promoting green tomato, and 'Lia' shows high and stable Spd levels throughout the maturation period. However, to be able to declare a tomato health promoting based on PAs content and composition, additional studies are needed, not least connecting animal/human models with knowledge on tomato genotypes and maturation. Furthermore, the procarcinogenic properties of PAs in cancer patients [16-21] have to be further studied to secure a positive and not a negative effect from the intake of certain tomato genotypes rich in PAs.

\section{Conclusions}

Content and composition of $P A s$ vary significantly among tomato genotypes. Thus, high content genotypes of both Tpa and of the different types of PAs can be differentiated and used for breeding and production of health promoting tomatoes for direct consumption or for use as food additives. Variation over the maturation period, both in Tpa content and in content of specific PAs, was inconsistent among genotypes, and needs to be characterized separately for every genotype. However, this variation creates opportunities to select and produce both health promoting green and red tomatoes as well as those that are stable over the entire production period. The found variation in tomato genotypes and over the maturation period calls for extended studies to understand these implications for human health. The fact that the $P A$ content and composition vary over the tomato maturation period and do so differently for different genotypes most likely affects the plant and fruit development as well as physiological characteristics, including tolerance to stresses and diseases. However, such relationships need further evaluation, as do the connections of specific tomatoes at specific maturity stages on human health.

Supplementary Materials: The following are available online at https:/ /www.mdpi.com/article/10 .3390/horticulturae7090300/s1; Table S1: Mass Calculation for Putrescine, Spermidine and Spermine bound with Dansyl Chloride; Table S2: Mean Square Value from Analysis of Variance (ANOVA) of Polyamines Contents+ and Quality Traits++ in Tomato Samples as Affected by Genotype and Maturity Stage; Table S3: Mean values ( $\mu \mathrm{g} / \mathrm{g}$ DW) of Polyamines in Tomato at Different Maturity Stages from Various Studies; Table S4: Mean values ( $\mu \mathrm{g} / \mathrm{g} D W)$ of Polyamines in Tomato at Different Maturity Stages.; Figure S1: Representative samples showing the different maturation stages of tomatoes from various genotypes; Figure S2: Polyamines chromatogram; Figure S3: Loading plot generated from PCA on values of each tomato evaluated, from quality traits.

Author Contributions: Conceptualization, M.E.O., A.C.Q. and E.J.; methodology, E.E.V.G. and K.-E.G.; validation, M.E.O. and K.-E.G.; formal analysis, E.J. and E.E.V.G.; investigation, E.E.V.G.; resources, E.J. and M.E.O.; data curation, K.-E.G.; writing-original draft preparation, E.E.V.G.; 
writing-review and editing, K.-E.G., A.C.Q., E.J. and M.E.O.; visualization, E.E.V.G., M.E.O. and E.J.; supervision, E.J. and M.E.O.; project administration, E.J.; funding acquisition, E.J. and M.E.O. All authors have read and agreed to the published version of the manuscript.

Funding: This research was funded by the Swedish International Development Cooperation Agency (Sida), grant no 75000554-08.

Institutional Review Board Statement: Not applicable.

Informed Consent Statement: Not applicable.

Data Availability Statement: Data is available by contact with the first author and is stored at the SLU server.

Acknowledgments: The authors express their gratitude to the Swedish University of Agricultural Science SLU and Universidad Mayor de San Simón (UMSS) for the educational and logistic support and to the Bolivian National Center of Horticultural Seed Production (CNPSH) for providing part of the plant material used in this study.

Conflicts of Interest: The authors declare no conflict of interest. The funders had no role in the design of the study; in the collection, analyses, or interpretation of data; in the writing of the manuscript; or in the decision to publish the results.

\section{References}

1. Brown, R.C.; Brown, T.R. The Biorenewable Resource Base. In Biorenewable Resources: Engineering New Products from Agriculture; John Wiley \& Sons Inc.: Chichester, West Sussex, UK, 2014; p. 388, ISBN 978-1-118-52492-3.

2. Nadaria-Hoke, S. Structural and Thermodynamic Characterization of Spermidine and Spermine Synthases. Ph.D. Thesis, Pennsylvania State University, State College, PA, USA, 2009.

3. Handa, A.K.; Fatima, T.; Mattoo, A.K. Polyamines: Bio-molecules with diverse functions in plant and human health and disease. Front. Chem. 2018, 6, 10. [CrossRef]

4. Salvi, D.; Tavladoraki, P. The tree of life of polyamine oxidases. Sci. Rep. 2020, 10, 17858. [CrossRef]

5. Bae, D.-H.; Lane, D.J.R.; Jansson, P.J.; Richardson, D.R. The old and new biochemistry of polyamines. Biochim. Biophys. Acta (BBA) Gen. Subj. 2018, 1862, 2053-2068. [CrossRef] [PubMed]

6. Bagni, N.; Tassoni, A. Biosynthesis, oxidation and conjugation of aliphatic polyamines in higher plants. Amino Acids 2001, 20, 301-317. [CrossRef] [PubMed]

7. Tsaniklidis, G.; Kotsiras, A.; Tsafouros, A.; Roussos, P.A.; Aivalakis, G.; Katinakis, P.; Delis, C. Spatial and temporal distribution of genes involved in polyamine metabolism during tomato fruit development. Plant Physiol. Biochem. 2016, 100, 27-36. [CrossRef]

8. Sánchez-Rodríguez, E.; Romero, L.; Ruiz, J.M. Accumulation of free polyamines enhances the antioxidant response in fruits of grafted tomato plants under water stress. J. Plant Physiol. 2016, 190, 72-78. [CrossRef] [PubMed]

9. Romero, F.M.; Maiale, S.J.; Rossi, F.R.; Marina, M.; Ruíz, O.A.; Gárriz, A. Polyamine metabolism responses to biotic and abiotic stress. In Polyamines; Alcázar, R., Tiburcio, A.F., Eds.; Springer: New York, NY, USA, 2018; Volume 1694, pp. 37-49, ISBN 978-1-4939-7397-2.

10. Mehta, R.A.; Cassol, T.; Li, N.; Ali, N.; Handa, A.K.; Mattoo, A.K. Engineered polyamine accumulation in tomato enhances phytonutrient content, juice quality, and vine life. Nat. Biotechnol. 2002, 20, 613-618. [CrossRef]

11. Koushesh saba, M.; Arzani, K.; Barzegar, M. Postharvest polyamine application alleviates chilling injury and affects apricot storage ability. J. Agric. Food Chem. 2012, 60, 8947-8953. [CrossRef] [PubMed]

12. Matsumoto, M.; Kibe, R.; Ooga, T.; Aiba, Y.; Kurihara, S.; Sawaki, E.; Koga, Y.; Benno, Y. Impact of intestinal microbiota on intestinal luminal metabolome. Sci. Rep. 2012, 2, 233. [CrossRef]

13. Muñoz-Esparza, N.C.; Latorre-Moratalla, M.L.; Comas-Basté, O.; Toro-Funes, N.; Veciana-Nogués, M.T.; Vidal-Carou, M.C. Polyamines in food. Front. Nutr. 2019, 6, 108. [CrossRef] [PubMed]

14. Soda, K.; Kano, Y.; Chiba, F. Food polyamine and cardiovascular disease-An epidemiological study. GJHS 2012, 4, 170. [CrossRef]

15. Nilsson, B.-O.; Persson, L. Beneficial effects of spermidine on cardiovascular health and longevity suggest a cell type-specific import of polyamines by cardiomyocytes. Biochem. Soc. Trans. 2019, 47, 265-272. [CrossRef] [PubMed]

16. Madeo, F.; Eisenberg, T.; Pietrocola, F.; Kroemer, G. Spermidine in health and disease. Science 2018, 359, eaan2788. [CrossRef] [PubMed]

17. Soda, K.; Dobashi, Y.; Kano, Y.; Tsujinaka, S.; Konishi, F. Polyamine-rich food decreases age-associated pathology and mortality in aged mice. Exp. Gerontol. 2009, 44, 727-732. [CrossRef]

18. Kiechl, S.; Pechlaner, R.; Willeit, P.; Notdurfter, M.; Paulweber, B.; Willeit, K.; Werner, P.; Ruckenstuhl, C.; Iglseder, B.; Weger, S.; et al. Higher spermidine intake is linked to lower mortality: A Prospective population-based study. Am. J. Clin. Nutr. 2018, 108, 371-380. [CrossRef] [PubMed]

19. Hirano, R.; Shirasawa, H.; Kurihara, S. Health-promoting effects of dietary polyamines. Med. Sci. 2021, 9, 8. [CrossRef] 
20. Eisenberg, T.; Knauer, H.; Schauer, A.; Büttner, S.; Ruckenstuhl, C.; Carmona-Gutierrez, D.; Ring, J.; Schroeder, S.; Magnes, C.; Antonacci, L.; et al. Induction of autophagy by spermidine promotes longevity. Nat. Cell. Biol. 2009, 11, 1305-1314. [CrossRef]

21. Miao, H.; Ou, J.; Peng, Y.; Zhang, X.; Chen, Y.; Hao, L.; Xie, G.; Wang, Z.; Pang, X.; Ruan, Z.; et al. Macrophage ABHD5 promotes colorectal cancer growth by suppressing spermidine production by SRM. Nat. Commun. 2016, 7, 11716. [CrossRef] [PubMed]

22. Fan, J.; Feng, Z.; Chen, N. Spermidine as a target for cancer therapy. Pharmacol. Res. 2020, 159, 104943. [CrossRef] [PubMed]

23. McNamara, K.M.; Gobert, A.P.; Wilson, K.T. The role of polyamines in gastric cancer. Oncogene 2021, 40, 4399-4412. [CrossRef]

24. Casero, R.A.; Murray Stewart, T.; Pegg, A.E. Polyamine metabolism and cancer: Treatments, challenges and opportunities. Nat. Rev. Cancer 2018, 18, 681-695. [CrossRef] [PubMed]

25. Vargas, A.J.; Ashbeck, E.L.; Wertheim, B.C.; Wallace, R.B.; Neuhouser, M.L.; Thomson, C.A.; Thompson, P.A. Dietary polyamine intake and colorectal cancer risk in postmenopausal women. Am. J. Clin. Nutr. 2015, 102, 411-419. [CrossRef] [PubMed]

26. Huang, C.-Y.; Fang, Y.-J.; Abulimiti, A.; Yang, X.; Li, L.; Liu, K.-Y.; Zhang, X.; Feng, X.-L.; Chen, Y.-M.; Zhang, C.-X. Dietary polyamines intake and risk of colorectal cancer: A case-control study. Nutrients 2020, 12, 3575. [CrossRef] [PubMed]

27. Wawrzyniak, M.; Groeger, D.; Frei, R.; Ferstl, R.; Wawrzyniak, P.; Krawczyk, K.; Pugin, B.; Barcik, W.; Westermann, P.; Dreher, A.; et al. Spermidine and spermine exert protective effects within the lung. Pharmacol. Res. Perspect. 2021, 9. [CrossRef] [PubMed]

28. Sagar, N.A.; Tarafdar, S.; Agarwal, S.; Tarafdar, A.; Sharma, S. Polyamines: Functions, metabolism, and role in human disease management. Med. Sci. 2021, 9, 44. [CrossRef]

29. Simon, P.W. Progress toward increasing intake of dietary nutrients from vegetables and fruits: The case for a greater role for the horticultural sciences. Horts 2014, 49, 112-115. [CrossRef]

30. Garcia-Mier, L.; Jimenez-García, S.N.; Salazar, C.S.; Contreras-Medina, L.M.; Escalante, K.E.; Martinez, C.G.; García-Trejo, J.F.; Guevara-Gonzalez, R.G.; Feregrino-Perez, A.A. Strategies that influence the production of secondary metabolites in plants. In Nutritional Quality Improvement in Plants; Jaiwal, P.K., Chhillar, A.K., Chaudhary, D., Jaiwal, R., Eds.; Concepts and Strategies in Plant Sciences; Springer International Publishing: Cham, Germany, 2019; pp. 231-270, ISBN 978-3-319-95353-3.

31. Hou, Y.; He, W.; Hu, S.; Wu, G. Composition of polyamines and amino acids in plant-source foods for human consumption. Amino Acids 2019, 51, 1153-1165. [CrossRef]

32. Takahashi, T. Plant polyamines. Plants 2020, 9, 511. [CrossRef] [PubMed]

33. Guo, J.; Wang, S.; Yu, X.; Dong, R.; Li, Y.; Mei, X.; Shen, Y. Polyamines regulate strawberry fruit ripening by abscisic acid, auxin, and ethylene. Plant Physiol. 2018, 177, 339-351. [CrossRef] [PubMed]

34. Fortes, A.M.; Agudelo-Romero, P.; Silva, M.S.; Ali, K.; Sousa, L.; Maltese, F.; Choi, Y.H.; Grimplet, J.; Martinez- Zapater, J.M.; Verpoorte, R.; et al. Transcript and metabolite analysis in trincadeira cultivar reveals novel information regarding the dynamics of grape ripening. BMC Plant Biol. 2011, 11, 149. [CrossRef]

35. Ziosi, V.; Bregoli, A.M.; Bonghi, C.; Fossati, T.; Biondi, S.; Costa, G.; Torrigiani, P. Transcription of ethylene perception and biosynthesis genes is altered by putrescine, spermidine and aminoethoxyvinylglycine (AVG) during ripening in peach fruit (Prunus Persica). New Phytol. 2006, 172, 229-238. [CrossRef]

36. Yahia, E.M.; Contreras-Padilla, M.; Gonzalez-Aguilar, G. Ascorbic acid content in relation to ascorbic acid oxidase activity and polyamine content in tomato and bell pepper fruits during development, maturation and senescence. LWT Food Sci. Technol. 2001, 34, 452-457. [CrossRef]

37. Osorio, S.; Alba, R.; Nikoloski, Z.; Kochevenko, A.; Fernie, A.R.; Giovannoni, J.J. Integrative comparative analyses of transcript and metabolite profiles from pepper and tomato ripening and development stages uncovers species-specific patterns of network regulatory behavior. Plant Physiol. 2012, 159, 1713-1729. [CrossRef]

38. Gharbi, E.; Martínez, J.-P.; Benahmed, H.; Fauconnier, M.-L.; Lutts, S.; Quinet, M. Salicylic acid differently impacts ethylene and polyamine synthesis in the glycophyte Solanum Lycopersicum and the wild-related halophyte Solanum Chilense exposed to mild salt stress. Physiol. Plantarum. 2016, 158, 152-167. [CrossRef] [PubMed]

39. FAO. Faostat: Crops-Production Quantity-World-Vegetables Primary. Available online: http://www.fao.org/faostat/en/\#data/ QC (accessed on 26 March 2021).

40. Rick, C.M. The Tomato. Sci. Am. 1978, 239, 76-89. [CrossRef]

41. Altman, P.L.; Dittmer, D.S. Metabolism; Biological handbooks; Federation of American Societies for Experimental Biology: Rockville, MD, USA, 1968.

42. Gupta, A.; Pandey, R.; Sinha, R.; Chowdhary, A.; Pal, R.; Rajam, M. Improvement of post-harvest fruit characteristics in tomato by fruit-specific over-expression of oat arginine decarboxylase gene. Plant Growth Regul. 2019, 88, 1-11. [CrossRef]

43. Neily, M.H.; Matsukura, C.; Maucourt, M.; Bernillon, S.; Deborde, C.; Moing, A.; Yin, Y.-G.; Saito, T.; Mori, K.; Asamizu, E.; et al. Enhanced polyamine accumulation alters carotenoid metabolism at the transcriptional level in tomato fruit over-expressing spermidine synthase. J. Plant Physiol. 2011, 168, 242-252. [CrossRef]

44. Pedro, A.M.K.; Ferreira, M.M.C. Nondestructive determination of solids and carotenoids in tomato products by near-infrared spectroscopy and multivariate calibration. Anal. Chem. 2005, 77, 2505-2511. [CrossRef] [PubMed]

45. Akpolat, H.; Barineau, M.; Jackson, K.A.; Aykas, D.P.; Rodriguez-Saona, L.E. Portable infrared sensing technology for phenotyping chemical traits in fresh market tomatoes. LWT 2020, 124, 109164. [CrossRef]

46. Rouphael, Y.; Kyriacou, M.C. Quality and safety of fresh fruits and vegetables at harvest. Sci. Hortic. 2018, 239, 78-79. [CrossRef]

47. U.S. Department of Agriculture Index of Official Visual Aids. Available online: https://www.ams.usda.gov/sites/default/files/ media/Official\%20Inventory\%20of\%20FV\%20Inspection\%20Aids.pdf (accessed on 16 September 2019). 
48. Rodríguez, G.R.; Muños, S.; Anderson, C.; Sim, S.-C.; Michel, A.; Causse, M.; Gardener, B.B.M.; Francis, D.; van der Knaap, E. Distribution of SUN, OVATE, LC, and FAS in the tomato germplasm and the relationship to fruit shape diversity. Plant Physiol. 2011, 156, 275. [CrossRef] [PubMed]

49. Bergquist, S.Å; Gertsson, U.E.; Olsson, M.E. Influence of growth stage and postharvest storage on ascorbic acid and carotenoid content and visual quality of baby spinach (Spinacia Oleracea, L.). J. Sci. Food Agric. 2006, 86, 346-355. [CrossRef]

50. López Camelo, A.F.; Gómez, P.A. Comparison of color indexes for tomato ripening. Hortic. Bras. 2004, 22, 534-537. [CrossRef]

51. McGuire, R.G. Reporting of objective color measurements. Hort. Sci. 1992, 27, 1254-1255. [CrossRef]

52. Xu, S.; Sun, X.; Lu, H.; Yang, H.; Ruan, Q.; Huang, H.; Chen, M. Detecting and Monitoring the flavor of tomato (Solanum Lycopersicum) under the Impact of postharvest handlings by physicochemical parameters and electronic nose. Sensors 2018, 18, 1847. [CrossRef] [PubMed]

53. Tolesa, G.N.; Workneh, T.S.; Melesse, S.F. Logistic regression analysis of marketability of tomato fruit harvested at different maturity stages and subjected to disinfection, storage condition and storage period treatments. Biol. Agric. Hortic. 2018, 34, 40-52. [CrossRef]

54. Chen, D.; Shao, Q.; Yin, L.; Younis, A.; Zheng, B. Polyamine function in plants: Metabolism, regulation on development, and roles in abiotic stress responses. Front. Plant Sci. 2019, 9, 1945. [CrossRef]

55. Hatmi, S.; Gruau, C.; Trotel-Aziz, P.; Villaume, S.; Rabenoelina, F.; Baillieul, F.; Eullaffroy, P.; Clément, C.; Ferchichi, A.; Aziz, A. Drought stress tolerance in grapevine involves activation of polyamine oxidation contributing to improved immune response and low susceptibility to botrytis cinerea. J. Exp. Botany 2015, 66, 775-787. [CrossRef] [PubMed]

56. Aziz, A.; Brun, O.; Audran, J.-C. Involvement of polyamines in the control of fruitlet physiological abscission in grapevine (Vitis Vinifera). Physiol. Plant. 2001, 113, 50-58. [CrossRef]

57. Flores, H.E.; Galston, A.W. Analysis of polyamines in higher plants by high performance liquid chromatography. Plant Physiol. 1982, 69, 701-706. [CrossRef] [PubMed]

58. Eerola, S.; Tiina, R.; Kuitunen, K. Rokka mervi biogenic amines. HPLC determination in foods. NMKL Method 2013, 1, 1-12.

59. Buranaphalin, S. Pharmaceutical Analysis of Polyamines and Aminoglycosides; University of Bath: Bath, UK, 2009.

60. Figàs, M.R.; Prohens, J.; Raigón, M.D.; Fita, A.; García-Martínez, M.D.; Casanova, C.; Borràs, D.; Plazas, M.; Andújar, I.; Soler, S. Characterization of composition traits related to organoleptic and functional quality for the differentiation, selection and enhancement of local varieties of tomato from different cultivar groups. Food Chem. 2015, 187, 517-524. [CrossRef]

61. Johansson, E.; Hussain, A.; Kuktaite, R.; Andersson, S.C.; Olsson, M.E. Contribution of organically grown crops to human health. Int. J. Environ. Res. Public Health 2014, 11, 3870. [CrossRef] [PubMed]

62. Johansson, E.; Branlard, G.; Cuniberti, M.; Flagella, Z.; Hüsken, A.; Nurit, E.; Peña, R.J.; Sissons, M.; Vazquez, D. Genotypic and environmental effects on wheat technological and nutritional quality. In Wheat Quality For Improving Processing And Human Health; Igrejas, G., Ikeda, T.M., Guzmán, C., Eds.; Springer International Publishing: Cham, Germnay, 2020; pp. 171-204, ISBN 978-3-030-34162-6.

63. Vagiri, M.; Ekholm, A.; Öberg, E.; Johansson, E.; Andersson, S.C.; Rumpunen, K. Phenols and ascorbic acid in black currants (Ribes nigrum L.): Variation due to genotype, location and year. J. Agric. Food Chem. 2013, 61, 9298-9306. [CrossRef] [PubMed]

64. Andersson, S.C.; Olsson, M.E.; Gustavsson, K.-E.; Johansson, E.; Rumpunen, K. Tocopherols in rose hips (Rosa Spp.) during Ripening. J. Sci. Food Agric. 2012, 92, 2116-2121. [CrossRef]

65. Johansson, E.; Kuktaite, R.; Andersson, A.; Prieto-Linde, M.L. Protein polymer build-up during wheat grain development: Influences of temperature and nitrogen timing. J. Sci. Food Agric. 2005, 85, 473-479. [CrossRef]

66. Andersson, S.C.; Olsson, M.E.; Johansson, E.; Rumpunen, K. Carotenoids in sea buckthorn (Hippophae Rhamnoides, L.) berries during ripening and use of pheophytin $a$ as a maturity marker. J. Agric. Food Chem. 2009, 57, 250-258. [CrossRef]

67. Arias, R.; Lee, T.-C.; Logendra, L.; Janes, H. Correlation of lycopene measured by HPLC with the $L^{*}, a^{*}, b^{*}$ color readings of a hydroponic tomato and the relationship of maturity with color and lycopene content. J. Agric. Food Chem. 2000, 48, 1697-1702. [CrossRef]

68. Opara, U.L.; Al-Ani, M.R.; Al-Rahbi, N.M. Effect of fruit ripening stage on physico-chemical properties, nutritional composition and antioxidant components of tomato (Lycopersicum Esculentum) cultivars. Food Bioprocess Technol. 2012, 5, 3236-3243. [CrossRef]

69. Clément, A.; Dorais, M.; Vernon, M. Multivariate approach to the measurement of tomato maturity and gustatory attributes and their rapid assessment by vis-NIR spectroscopy. J. Agric. Food Chem. 2008, 56, 1538-1544. [CrossRef] [PubMed]

70. Wills, R.B.H.; McGlasson, B.; Joyce, D.; Graham, D. Postharvest: An Introduction to the Physiology and Handling of Fruit, Vegetables and Ornamentals; University of Texas Press: Austin, TX, USA, 2007; ISBN 978-1-84593-227-5.

71. Zsom-Muha, V.; Zsom, T.; Felföldi, J. In-vivo measurement of tomato firmness. Acta Hortic. 2008, 677-684. [CrossRef]

72. Nambeesan, S.; Datsenka, T.; Ferruzzi, M.G.; Malladi, A.; Mattoo, A.K.; Handa, A.K. Overexpression of yeast spermidine synthase impacts ripening, senescence and decay symptoms in tomato: Polyamines enhance shelf life in tomato. Plant J. 2010, 63, 836-847. [CrossRef] [PubMed]

73. Madhulatha, P.; Gupta, A.; Gupta, S.; Kumar, A.; Pal, R.K.; Rajam, M.V. Fruit-specific over-expression of human sadenosylmethionine decarboxylase gene results in polyamine accumulation and affects diverse aspects of tomato fruit development and quality. J. Plant Biochem. Biotechnol. 2014, 23, 151-160. [CrossRef]

74. Anwar, R.; Fatima, S.; Mattoo, A.K.; Handa, A.K. Fruit architecture in polyamine-rich tomato germplasm is determined via a medley of cell cycle, cell expansion, and fruit shape genes. Plants 2019, 8, 387. [CrossRef] 
75. Goyal, R.K.; Fatima, T.; Topuz, M.; Bernadec, A.; Sicher, R.; Handa, A.K.; Mattoo, A.K. Pathogenesis-related protein 1b1 (PR1b1) is a major tomato fruit protein responsive to chilling temperature and upregulated in high polyamine transgenic genotypes. Front. Plant Sci. 2016, 7. [CrossRef]

76. Nishibori, N.; Fujihara, S.; Akatuki, T. Amounts of polyamines in foods in Japan and Intake by Japanese. Food Chem. 2007, 100, 491-497. [CrossRef]

77. Moret, S.; Smela, D.; Populin, T.; Conte, L.S. A Survey on free biogenic amine content of fresh and preserved vegetables. Food Chem. 2005, 89, 355-361. [CrossRef]

78. Harpaz-Saad, S.; Yoon, G.M.; Mattoo, A.K.; Kieber, J.J. The Formation of ACC and competition between polyamines and ethylene for SAM. In Annual Plant Reviews Volume 44; McManus, M.T., Ed.; Wiley-Blackwell: Oxford, UK, 2012; pp. 53-81. ISBN 978-1-118-22308-6.

79. Ben-arie, R.; Lurie, S.; Mattoo, A. Temperature-dependent inhibitory effects of calcium and spermine on ethylene biosynthesis in apple discs correlate with changes in microsomal membrane microviscosit. Plant Sci. Lett. 1982, 24, 239-247. [CrossRef]

80. Apelbaum, A.; Burgoon, A.C.; Anderson, J.D.; Lieberman, M.; Ben-Arie, R.; Mattoo, A.K. Polyamines inhibit biosynthesis of ethylene in higher plant tissue and fruit protoplasts. Plant Physiol. 1981, 68, 453-456. [CrossRef]

81. Gao, F.; Mei, X.; Li, Y.; Guo, J.; Shen, Y. Update on the roles of polyamines in fleshy fruit ripening, senescence, and quality. Front. Plant Sci. 2021, 12, 610313. [CrossRef]

82. Mattoo, A.K.; Minocha, S.C.; Minocha, R.; Handa, A.K. Polyamines and cellular metabolism in plants: Transgenic approaches reveal different responses to diamine putrescine versus higher polyamines spermidine and spermine. Amino Acids 2010, 38, 405-413. [CrossRef]

83. Li, N.; Parsons, B.L.; Liu, D.; Mattoo, A.K. Accumulation of wound-inducible ACC synthase transcript in tomato fruit is inhibited by salicylic acid and polyamines. Plant Mol. Biol. 1992, 18, 477-487. [CrossRef]

84. Zhang, T.; John, S.; Wang, Y. Cultivar and Agricultural Management on Lycopene and Vitamin C Contents in Tomato Fruits; CRC Press: Boca Raton, FL, USA, 2008; pp. 27-45.

85. Gómez, M.D.; Vera-Sirera, F.; Pérez-Amador, M.A. Molecular programme of senescence in dry and fleshy fruits. J. Exp. Botany 2013, 65, 4515-4526. [CrossRef]

86. Morilla, A.; García, J.M.; Albi, M.A. Free polyamine contents and decarboxylase activities during tomato development and ripening. J. Agric. Food Chem. 1996, 44, 2608-2611. [CrossRef]

87. Wi, S.J.; Kim, W.T.; Park, K.Y. Overexpression of carnation S-adenosylmethionine decarboxylase gene generates a broad-spectrum tolerance to abiotic stresses in transgenic tobacco plants. Plant Cell Rep. 2006, 25, 1111-1121. [CrossRef] [PubMed]

88. Alcázar, R.; Altabella, T.; Marco, F.; Bortolotti, C.; Reymond, M.; Koncz, C.; Carrasco, P.; Tiburcio, A.F. Polyamines: Molecules with regulatory functions in plant abiotic stress tolerance. Planta 2010, 231, 1237-1249. [CrossRef]

89. Kasukabe, Y.; He, L.; Nada, K.; Misawa, S.; Ihara, I.; Tachibana, S. Overexpression of spermidine synthase enhances tolerance to multiple environmental stresses and up-regulates the expression of various stress-regulated genes in transgenic Arabidopsis Thaliana. Plant Cell Physiol. 2004, 45, 712-722. [CrossRef] [PubMed]

90. Kasukabe, Y.; He, L.; Watakabe, Y.; Otani, M.; Shimada, T.; Tachibana, S. Improvement of environmental stress tolerance of sweet potato by introduction of genes for spermidine synthase. Plant Biotechnol. 2006, 23, 75-83. [CrossRef]

91. He, L.; Ban, Y.; Inoue, H.; Matsuda, N.; Liu, J.; Moriguchi, T. Enhancement of spermidine content and antioxidant capacity in transgenic pear shoots overexpressing apple spermidine synthase in response to salinity and hyperosmosis. Phytochemistry 2008, 69, 2133-2141. [CrossRef] [PubMed]

92. Wen, X.-P.; Pang, X.-M.; Matsuda, N.; Kita, M.; Inoue, H.; Hao, Y.-J.; Honda, C.; Moriguchi, T. Over-expression of the apple spermidine synthase gene in pear confers multiple abiotic stress tolerance by altering polyamine titers. Transgenic Res. 2008, 17, 251-263. [CrossRef] [PubMed]

93. Fortes, A.M.; Agudelo-Romero, P. Polyamine metabolism in climacteric and non-climacteric fruit ripening. In Polyamines; Alcázar, R., Tiburcio, A.F., Eds.; Springer: New York, NY, USA, 2018; Volume 1694, pp. 433-447. ISBN 978-1-4939-7397-2.

94. Pegg, A.E. Functions of polyamines in mammals. J. Biol. Chem. 2016, 291, 14904-14912. [CrossRef] [PubMed]

95. Hussain, T.; Tan, B.; Ren, W.; Rahu, N.; Dad, R.; Kalhoro, D.H.; Yin, Y. Polyamines: Therapeutic perspectives in oxidative stress and inflammatory diseases. Amino Acids 2017, 49, 1457-1468. [CrossRef] [PubMed]

96. Saiki, S.; Sasazawa, Y.; Fujimaki, M.; Kamagata, K.; Kaga, N.; Taka, H.; Li, Y.; Souma, S.; Hatano, T.; Imamichi, Y.; et al. A metabolic profile of polyamines in parkinson disease: A promising biomarker. Ann. Neurol. 2019, 86, 251-263. [CrossRef] [PubMed]

97. Liu, P.; Fleete, M.S.; Jing, Y.; Collie, N.D.; Curtis, M.A.; Waldvogel, H.J.; Faull, R.L.M.; Abraham, W.C.; Zhang, H. Altered arginine metabolism in Alzheimer's disease brains. Neurobiol. Aging 2014, 35, 1992-2003. [CrossRef] [PubMed]

98. Eisenberg, T.; Abdellatif, M.; Schroeder, S.; Primessnig, U.; Stekovic, S.; Pendl, T.; Harger, A.; Schipke, J.; Zimmermann, A.; Schmidt, A. Cardioprotection and lifespan extension by the natural polyamine spermidine. Nat. Med. 2016, 22, 1428-1438. [CrossRef] [PubMed] 